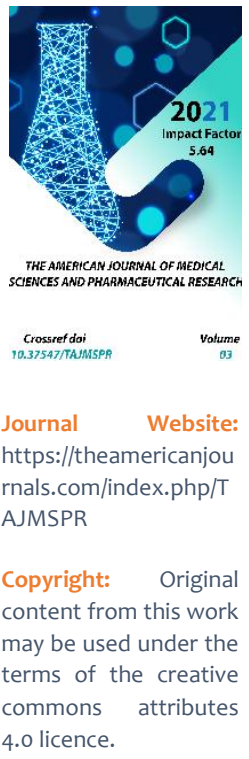

\title{
Features Of Verticalization In Early Rehabilitation Of Ischaemic Stroke And Diabetes Patients
}

\author{
Pulatov Sadriddin Sayfullaevich \\ Candidate Of Medical Sciences, Associate Professor, Head Of Department Rehabilitation \\ Medicine And Sports Medicine, Bukhara State Medical Institute, Uzbekistan \\ Ruziev Feruz Giyasovich \\ Neurologist, Republican Scientific Centre For Emergency Medical Care, Bukhara Branch, \\ Uzbekistan
}

\section{ABSTRACT}

The risk of stroke in diabetic patients is significantly higher than in non-diabetic patients. Appropriate studies on the prevalence and characteristics of the onset of elderly diabetes with stroke in many countries are still lacking. Effective prevention and control still face enormous challenges. Older diabetic patients with osteoporosis need sensible intervention and treatment based on an individualised comprehensive assessment.

\section{KEYWORDS}

Stroke, Verticalization And Realization.

\section{INTRODUCTION}

The problem of stroke is becoming more and more urgent every year because the incidence of stroke is increasing in different age groups. According to statistics, stroke, along with high mortality, ranks first among the causes of primary disability. More than $15 \%$ of people who have had a stroke do not return to work, while $35 \%$ remain disabled and require medical and social care for the rest of their lives. The rehabilitation process is one of the most pressing issues, and the earlier the rehabilitation process begins, the more effective it becomes. $55-95 \%$ of patients with acute cerebral haemorrhage are kept in the ICU for more than 48 hours [1-3].A significant difficulty in rehabilitation measures in the acute period of stroke is presented not only by migraine neurological failures but also by associated lesions of the autonomic nervous system, including the development of orthostatic hypotension. Immobilisation syndrome (IS) is the most problematic 
measure of the rehabilitation process. $65-80 \%$ of patients with acute cerebral circulation disorders require immobilisation syndrome.

Is-complex is the limitation of the patient's motor and cognitive activity in acute central and peripheral nervous system lesions as a result of a complex of multi-organ disorders and neurophysiological organic disturbances. These symptoms, in particular cardiovascular failure, lead to orthostatic insufficiency (OSA) and gravity gradient disorder (GG). Orthostatic (postural) hypotension is an excessive decrease in blood pressure (BP) when taking an upright position. It is usually diagnosed as a decrease in systolic BP > $20 \mathrm{mmHg}$, diastolic BP by more than $10 \mathrm{mmHg}$ or both. This causes weakness, dizziness, disorientation or visual disturbances, which last from a few seconds to several minutes in a standing position and disappear quickly when you lie horizontally. Some patients lose their balance and fall, and experience syncope or even generalised convulsions. Physical exertion or overeating may exacerbate the symptoms. Most other associated symptoms and signs are related to the cause [4-7].

Orthostatic hypotension is a manifestation of abnormal blood pressure regulation against a background of various conditions, it is not an independent disease. Evidence increasingly shows that impaired control of postural haemodynamics increases the risk of cardiovascular disease and overall mortality. (OSE) is a symptom comorbidity complex of complex vegemotor failure, including $20 \mathrm{mmHg}$ systolic blood pressure.10 $\mathrm{mmHg}$ diastolic blood pressure. See the following autonomic disturbances: dizziness due to cerebral hypoperfusion, visual disturbances, cognitive impairment, memory impairment, inability to stand up, breathlessness, tachycardia, increased sweating, painful muscle cramps, oliguria, reduced urine output. Gravitational Gradient (GG) is the ratio of different body states in different gravitational fields of the Earth, the ability to maintain vital aspects, especially the ability to provide a complex serotype of reflexes. The only way to overcome immobilisation syndrome is to achieve verticalisation of the patient while maintaining the gravity gradient. Verticalisation is a therapeutic strategy for maintaining a normal, functioning body in a natural upright position, preventing and treating immobilisation syndrome in patients in any case. Verticalisation aims to maximise gravity $(\geq 80)^{\circ}$ storage or recovery, a prerequisite for the patient's work with any duration of gravity, is to carry out a process of rehabilitation. This is achieved by training to ensure the maintenance (restoration) of orthostatic adequate posture, muscle afferentation from the tendon receptors closing the joints of the lower limbs and vertebrae, appropriate effects on positonic and dynamic activity retention, vestibular and postural reflex reactions and automatisms, improved respiratory function, reflex maintenance, stasis during bowel and bladder emptying [6-8]. This specialist clinical trial aims to introduce their use in practice and evaluate their effectiveness by examining measures of care in the preparation and verticalisation of patients at risk of developing immobilisation syndrome in the early phase after stroke. It also includes the introduction of clinical evidence and conclusions from a synthesis study in updating recommendations for the implementation of the verticalisation process in patients.

Study objective: To evaluate the safety and efficacy of passive, active-passive and passive- 
manual methods of early rehabilitation in the acute period in patients with type 2 diabetes mellitus with ischaemic stroke using clinical and instrumental methods.

\section{MATERIALS AND METHODS}

The clinical study involved 32 patients who were treated with the diagnosis of "acute coronary circulation disorder of ischemic type on the background of type 2 diabetes mellitus" in the Bukhara branch of the Republican Center of Emergency Medical Care in January - June 2021 and 40 patients who were treated with the diagnosis of "acute coronary circulation disorder of ischemic type. The main group consisted of patients treated with ischaemic stroke, with a history of type 2 diabetes mellitus and with a diagnosis of diabetes mellitus in laboratory tests, and the comparison group consisted of patients with no history or laboratory tests of diabetes mellitus who had been diagnosed with ischaemic stroke. The following evaluation criteria were strictly observed in the examined patients: patients aged 35-70 years who were hospitalized in the first 24 hours after the onset of the disease, regardless of the cause of ischemic stroke and in which cerebral artery was located, motor activity disorders of different gender, NIHSS scale were included.

On admission, patients at the Republican Scientific Centre for Emergency Medical Care, Bukhara branch underwent $C T$ scan with GE REVLUTION EVO (64 srez) General Electric (GE Healthcare) the USA, 2019 Y. Brain MRI for suspected lacunar stroke or stroke focus located in the cerebral column was performed with a Siemens Magnette Avanto 1.5 T brain $M R I$ machine - with magnetic field induction of 1.5 Tesla.
Patients with the following conditions were not included in the study: fainting and coma, with a body temperature above $37.2^{\circ} \mathrm{C}$, systolic blood pressure of $160 \mathrm{mmHg}$ diastolic blood pressure of $100 \mathrm{~mm}$. patients with elevated mercury column, severe cardiovascular insufficiency, pulmonary embolism, acute myocardial infarction, severe cardiac rhythm disturbances, patients with stages 3-4 diabetic nephropathy. In light of the requirement for the latter selection, the proportion of patients with a cardioembolic type of ischaemic stroke has decreased significantly [9-11]. In the study, all patients who had passed therapeutic window time and who had a confirmed diagnosis of ischaemic stroke underwent a verticalisation procedure during treatment with drugs against cerebral oedema, neuroprotection and improvement of blood rheology. Several neurological scales and tests were used to assess changes in the patient's condition. Before the verticalisation procedure, using the PLR (passive leg raising test) and the BPS (Behavioral pain scale) pain expression test, the patient's state of autonomic stasis and absence of pain limitations were assessed. Blood pressure, heart rate, respiration and $\mathrm{SpO}_{2}$ were monitored during the verticalisation process. Patients underwent passive, active-passive manual and active verticalisation in a functional bed according to their somatic condition and the results of the PLR and BPS tests. Determination of readiness for verticalisation and operation begins on the first day of onset. $1-48^{\circ}$ when the PLR and BPS tests are positive from $0-15$ hours after onset; $15-30^{\circ}$ when the results are negative, with the upper body supported over the head or lower back for a prolonged period of time. Body condition in patients with PLR and BPS test negative 2 days 
after onset $30^{\circ}-45^{\circ}-60^{\circ}-75^{\circ}-90^{\circ}$ stepwise angulation.

The number of breaths, pulse, blood pressure and SPO2 were monitored for 15 minutes when the body position was elevated by $15^{\circ}$. In cases where the change in clinical parameters did not exceed $20 \%$, the operation was continued for 15 minutes and the body position was returned to the previous position, after the patient had been held in a calm state for 2 hours, in addition to the previous position, he was verticalised again by $15^{\circ}$. In cases where the change in clinical parameters exceeded $20 \%$, the patient quickly returned to the previous position and vital signs normalised, the verticalisation procedure was resumed after 24 hours.

Table 1. Main clinical features in patients

\begin{tabular}{|c|c|c|c|}
\hline \multicolumn{2}{|c|}{ Main indicators } & $\begin{array}{l}\text { I group } \\
\text { Main group }\end{array}$ & $\begin{array}{c}\text { II group } \\
\text { Control group }\end{array}$ \\
\hline \multicolumn{2}{|c|}{ Total number of patients } & $32(100 \%)$ & $40(100 \%)$ \\
\hline \multirow[t]{2}{*}{ Gender } & Men & $20(62,5 \%)$ & $23(57,5 \%)$ \\
\hline & Women & $12(37,5 \%)$ & $17(42,5 \%)$ \\
\hline \multicolumn{2}{|c|}{ Age (year) } & $54,6 \pm 9,4$ & $57,7 \pm 7,3$ \\
\hline \multirow[t]{2}{*}{ Type } & Ischaemic & $32(100 \%)$ & $40(100 \%)$ \\
\hline & Hemorrhagic & - & - \\
\hline \multicolumn{2}{|c|}{ Lesion size, $\mathrm{cm}^{2}(\mathrm{n}=35)$} & $26,1 \pm 52,2$ & $15,7 \pm 42,4$ \\
\hline \multirow{3}{*}{$\begin{array}{l}\text { Lesion } \\
\text { Localisation }\end{array}$} & Right hemisphere & $17(53,1 \%)$ & $26(65,0 \%)$ \\
\hline & Left hemisphere & $13(40,6 \%)$ & $10(25,0 \%)$ \\
\hline & Brain stem & $2(6,3 \%)$ & $4(10,0 \%)$ \\
\hline \multirow{5}{*}{$\begin{array}{l}\text { Ischaemic stroke } \\
\text { pathogenetic type }\end{array}$} & Atherothrombotic & $13(30,0 \%)$ & $18(45,0 \%)$ \\
\hline & Cardioembolic & $3(16,7 \%)$ & $2(5,0 \%)$ \\
\hline & Lacunar & $5(16,7 \%)$ & $8(20,0 \%)$ \\
\hline & Other causes & $1(33,3 \%)$ & $0(0,0 \%)$ \\
\hline & Unknown causes & $10(22,5 \%)$ & $12(30,0 \%)$ \\
\hline \multicolumn{2}{|c|}{$\begin{array}{l}\text { From the beginning of the disease to the } \\
\text { study }\end{array}$} & $48,8+12,0$ & $48,3+16,5$ \\
\hline \multicolumn{2}{|c|}{ Body mass index,kg/m' } & $29,11 \pm 5,3$ & $28,2 \pm 4,6$ \\
\hline
\end{tabular}

Table 2. Indicators associated with diabetes

\begin{tabular}{|c|c|c|}
\hline Core indicators & $\begin{array}{c}\text { I group } \\
\text { Main group }\end{array}$ & $\begin{array}{c}\text { II group } \\
\text { Control group }\end{array}$ \\
\hline Blood glucose levels & $9,4 \pm 4,2$ ммоль/л & $4,6 \pm 2,1$ ммоль/л \\
\hline HgA1 & $7,6 \pm 3,6 \%$ & $4,7 \pm 2,3 \%$ \\
\hline Blood urea level & $12,6 \pm 4,4$ ммоль/л & $6,4 \pm 2,2$ ммоль/л \\
\hline Blood creatinine level & $86 \pm 24$ мкмоль/л & $54 \pm 18$ мкмоль/л \\
\hline Diabetic nephropathy I & $\mathrm{n}=20,(62,5 \%)$ & - \\
\hline Diabetic nephropathy II & $\mathrm{n}=12,(37,5 \%)$ & - \\
\hline
\end{tabular}




\begin{tabular}{|c|c|c|}
\hline Diabetic polyneuropathy II & $\mathrm{n}=28,(87,5 \%)$ & - \\
\hline Diabetic polyneuropathy III & $\mathrm{n}=4,(12,5 \%)$ & - \\
\hline Diabetic encephalopathy & $\mathrm{n}=24,(75 \%)$ & - \\
\hline
\end{tabular}

The clinical study showed that when comparing the main and control groups, both groups were predominantly affected in the right hemisphere, less often in the left hemisphere, and in the remaining cases in the cerebral column [10-13]. In both groups of patients, it was noted that ischemic stroke was accompanied by hypertension in most cases. The history showed that patients in the main group received hypoglycaemic, antiaggregant and antihypertensive drugs more often than patients in the additional group. Large-scale comparison of the main and additional groups: One of the main measurement criteria of the study is that all patients had motor disturbances in the condition $n=72$ (100\%). Migraine symptoms were also observed in the following proportions in the main and supplementary groups: prosoparesis in 23 (71.5\%) and 28 (70.0\%) patients, sensory disturbances-30 (93.7\%) and 34 (85.0\%), dysarthria-8 (25.0\%) and $17(42.5 \%)$, hemianopsia 4 (12.5\%) and6 (15.0\%), oculomotor nerve disturbances $7(15.0 \%) 21.8 \%$ ) and 9 (22.5\%) cases. On the NIHSS scale, the mean score was $12.4 \pm 4.3$ in the main group patients and $11.6 \pm 5.1$ in the additional group. The patients in the main group had an average $(R=0.01)$ to $30^{\circ}$ and $60^{\circ}$ rise angle $(R=0.005)$ decrease of arterial pressure during the 5 days of study, as well as reduction of arterial pressure $(R=0.001$ and $R=0.001$, respectively) in the initial and final cases. The angle of elevation in patients with stabilised haemodynamics indices on the 5 th and 7 th days was $30^{\circ}, 45^{\circ}, 60^{\circ} 75^{\circ}$ and up to $90^{\circ}$. On the 5th and 7 th days of treatment, the blood pressure normalised, and no significant difference in blood pressure was observed in the main and additional groups. The main condition is to achieve an adequate orthostatic state with stable haemodynamics. The literature cites a systolic blood pressure of 20 mmHg.A decrease in blood pressure is assessed as orthostatic hypotension, and training should be stopped when signs of cerebral circulatory insufficiency are observed. In addition, nausea and vomiting, dizziness, and other disturbances of consciousness are also assessed as a poor perception of verticalisation.

A risk factor analysis is performed when it is suspected that verticalisation is poorly perceived. In those cases where sensitivity was adequately maintained, a staged performance activation programme included pre-exercise functional tests, Tests and breath-holding exercises. However, a small number of patients in the groups had cases of inadequate admission during this test. Most patients with acute cerebral circulatory insufficiency received intensive palliative care for 7 days, which in turn made functional recovery very difficult. The flexibility and outcomes in the processes of verticalisation and early rehabilitation in diabetic patients (main group) and non-diabetic patients (supplementary group) in the acute period of ischaemic stroke were compared. Passive verticalisation of patients, including monitoring of respiratory and cardiovascular activity at $30^{\circ}, 45^{\circ}, 60^{\circ}, 75^{\circ}$ and a $90^{\circ}$ angle gradually increased. 
Table 3. Passive lower limb flexion (PLR) test results

\begin{tabular}{|c|c|c|c|c|}
\hline PLR test & $\begin{array}{c}\text { Main group } \\
(\mathrm{n})\end{array}$ & $\begin{array}{c}\text { Main group } \\
(\%)\end{array}$ & Control group (n) & $\begin{array}{c}\text { Control group } \\
(\%)\end{array}$ \\
\hline Complete negative & 7 & 21,9 & 25 & 62,5 \\
\hline 1-2 days. & 9 & 28,1 & 6 & 15 \\
\hline 3-4 days. & 14 & 43,8 & 8 & 20 \\
\hline 5-7 days & 2 & 6,3 & 1 & 2,5 \\
\hline Total & $\mathrm{n}-32$ & & $\mathrm{n}-40$ & \\
\hline
\end{tabular}

The PLR test results from Table 3 show that in the main group compared to the control group, the PLR test was positive on the first days in a large number of patients $(R \leq 0.001)$, while it also remained high in the next 3-5 days compared to the control group. In patients in the main group, the passive lower extremity test (PLR test) with passive verticalisation on the first day was positive in $78.1 \%$ of cases and in $37.5 \%$ of cases in the control group, And when combined with specific therapeutic procedures and early rehabilitation measures, there was a $6.25 \%$ reduction in the risk of ischaemic stroke, $2.3 \pm 0.07$ in the main group and $2.5 \%$ in the control group, to $8.15 \pm 0.2$ $(p \leq 0.001)$, showing that orthostatic patients were more likely than the control group to develop orthostasis.

Table 4. Results of the pain expression test (BPS test)

\begin{tabular}{|c|c|c|c|c|}
\hline PLR test & Main group (n) & Main group (\%) & Control group (n) & $\begin{array}{c}\text { Control group } \\
(\%)\end{array}$ \\
\hline $\begin{array}{c}\text { Complete } \\
\text { negative }\end{array}$ & 15 & 46,9 & 30 & 75 \\
\hline 1-2 days. & 12 & 37,5 & 8 & 20 \\
\hline 3-4 days. & 5 & 15,6 & 1 & 2,5 \\
\hline 5-7 days & 0 & 0,0 & 1 & 2,5 \\
\hline Total & $\mathrm{n}-32$ & & $\mathrm{n}-40$ & \\
\hline
\end{tabular}

According to the results, the VRS pain intensity test in diabetic ischaemic stroke patients was positive at 4 days, $53.1 \%$ of patients were positive at $7.8 \pm 0.24(r \leq 0.001)$ on the initial day, the control test was initially positive in $25 \%$ of patients at $6.4 \pm 0.31$ In cases where pain intensity was above 1-2 points on the VRS test, verticalization practice caused a delay.

Table 5. Results of verticalisation after 1-2 days of study

\begin{tabular}{|c|c|c|c|c|}
\hline $\begin{array}{c}\text { Verticalisation 1-2 } \\
\text { days }\end{array}$ & Main group (n) & $\begin{array}{c}\text { Main group } \\
(\%)\end{array}$ & $\begin{array}{c}\text { Control group } \\
(\mathrm{n})\end{array}$ & $\begin{array}{c}\text { Control group } \\
(\%)\end{array}$ \\
\hline $15-30^{\circ}$ & 30 & 93,7 & 22 & 55 \\
\hline
\end{tabular}




\begin{tabular}{|c|c|c|c|c|}
\hline $30-45^{\circ}$ & 1 & 3,1 & 12 & 30 \\
\hline $45-60^{\circ}$ & 1 & 3,1 & 6 & 15 \\
\hline $60-75^{\circ}$ & 0 & 0 & 0 & 0 \\
\hline $75-90^{\circ}$ & 0 & 0 & 0 & 0 \\
\hline Total & $\mathrm{n}-32$ & & $\mathrm{n}-40$ & \\
\hline
\end{tabular}

As shown in Table 5 above, dizziness was performed in $15-30^{\circ}$ (93.75\%) of patients in the main group at $30-45^{\circ}$ and $45-60^{\circ}$ if vertigo in 1 (3.1\%) patient within 1-2 days of examination. The control group was able to perform verticalization in $22(55 \%)$ patients at $15-30^{\circ}$ for $1-2$ days, $30-45^{\circ}$ in $12(30 \%)$ and $45-60^{\circ}$ in $6(15 \%)$ patients. $(r \leq 0.01)$, both groups did not perform verticalization at $60-90^{\circ}$ in any patient.

Table 5. Results of verticalisation after 5-7 days of study

\begin{tabular}{|c|c|c|c|c|}
\hline $\begin{array}{c}\text { Verticalisation 5-7 } \\
\text { days }\end{array}$ & Main group (n) & $\begin{array}{c}\text { Main group } \\
(\%)\end{array}$ & $\begin{array}{c}\text { Control group } \\
(\mathrm{n})\end{array}$ & $\begin{array}{c}\text { Control group } \\
(\%)\end{array}$ \\
\hline $15-30^{\circ}$ & 1 & 3,1 & 1 & 2,5 \\
\hline $30-45^{\circ}$ & 1 & 3,1 & 1 & 2,5 \\
\hline $45-60^{\circ}$ & 3 & 9,4 & 3 & 7,5 \\
\hline $60-75^{\circ}$ & 6 & 18,8 & 4 & 10 \\
\hline $75-90^{\circ}$ & 21 & 65,6 & 31 & 77,5 \\
\hline Total & $\mathrm{n}-32$ & & $\mathrm{n}-40$ & \\
\hline
\end{tabular}

On days 5-7 of the study, verticalisation of 75$90^{\circ}$ in patients who reached thermostasis was $65.6 \%$ in the main group and $77.5 \%$ in the control group. Thus, during passive verticalisation in patients with ischaemic stroke against the background of diabetes mellitus, on day 1-2 of the study, $93.8 \%$ of patients performed passive verticalisation measures, maintaining $15-30^{\circ}$, in the risk group - $55 \%$, and on the 5 th-7th days of the study, the rate of patients upright $90^{\circ}$ in the main group was $65,6 \%, 8,85 \pm 0,28$ and in the control group - 77,5\%, $16,7 \pm 0,4,(R<0,001$, in comparison with the control group of patients who had suffered strokes, slow formation of standing position was observed.

\section{CONCLUSIONS}

Thus, ischaemic stroke is relatively slow in dizziness in diabetic patients on the background, as well as a long course of orthostatic insufficiency, the manifestations of various degrees of diabetic polyneuropathy and diabetic nephropathy are relatively low recovery rates of neurological defects on the vertigo scale and NIHSS, long duration of early rehabilitation processes and their reduced effectiveness.

\section{REFERENCES}

1. Vereshagin N.V., Piradov M.A. (1999). Stroke: problem assessment". Neurology Journal. Moscow. (5). pp.47 . 
2. M.M. Tanashyan, K.V. Antonova, O.V. Lagoda, M.Yu. Maximova, M.V. Glebov, A.A. Shabalina. (2014). Acute circulatory disorders in the brain against the background of diabetes mellitus type 2. RAMS (Moscow)Clinica neurology, 8(3), pp.4-8.

3. Shmonin A.A. (2014). Modern approaches to rehabilitation of patients with stroke, 12 th session, St. Petersburg.

4. B.N. Mankovsky. (2010). Stroke in diabetic patients. Journal of Practical Angiology. 2(1).

5. Akhmatov, H., Aminov, A., \& Vahidova, A. M. (2019). The search for the most effective drug sin echinococcosis and pecilomycosis. Student research, 155158.

6. Vahidova A. M. et al. (2019). Fungi of the genus pacilomyces in human echinococcosis. World Science: Problems and Innovations. pp.186-190.

7. Shomurodov. K.E. (2010). Features of cytokine balance in gingival fluid at odontogenicphlegmon of maxillofacial area. Doctor-aspirant. 42(I). No.5.1.P.187-192.

8. Tillyashaykhov M. N., Rakhimov N. M. Khasanov Sh. T. (2019). Features of Clinical Manifestation of bladder cancer in young people. Doctor Bulletin. Samarkand. №2. P. 108-113.

9. Ilkhomovna, K. M., Eriyigitovich, I. S., \& Kadyrovich, K. N. (2020). Morphological Features of Microvascular Tissue of The Brain At Hemorrhagic Stroke. The American Journal of Medical Sciences and Pharmaceutical Research, 2(10), 53-59.

10. Kamalova, M. I., Khaidarov, N. K., \& Islamov, S. E. (2020).
Pathomorphological Features of hemorrhagic brain strokes. Journal of Biomedicine and Practice, 101-105.

11. Kadyrovich, K. N., Erkinovich, S. K., \& Ilhomovna, K. M. (2021). Microscopic Examination Of Postcapillary Cerebral Venues In Hemorrhagic Stroke. The American Journal of Medical Sciences and Pharmaceutical Research, 3(08), 69-73.

12. Shomurodov, K. E. (2010). Peculiarities of cytokine balance in gingival fluid at odontogenicphlegmon of maxillofacial area. The doctor-aspirant.-2010.-42 (5.1).-C, 187-192.

13. Isomov, M. M., \& Shomurodov, K. E. (2020). Peculiarities of rehabilitation of pregnant women with inflammatory diseases of maxillofacial area. In International scientific-practical conference" Modern aspects of complex dental rehabilitation of patients with maxillofacial defects" May (pp. 21-22). 